Original Research Article

\title{
Risk Factors for Late Rebleeding of Colonic Diverticular Bleeding in Elderly Individuals
}

\author{
Yoshinori Sato, Hiroshi Yasuda, Yusuke Nakamoto, Hirofumi Kiyokawa, Masaki Yamashita, Yasumasa Matsuo, \\ Tadateru Maehata, Hiroyuki Yamamoto and Fumio Itoh
}

Division of Gastroenterology and Hepatology, Department of Internal Medicine, St Marianna University School of Medicine, Kanagawa, Japan

\begin{abstract}
Objectives: This study aimed to examine the clinical characteristics of colonic diverticular bleeding (CDB) in elderly individuals.

Methods: This retrospective case-control study was conducted at a single tertiary center. A total of 519 patients (356 men and 163 women; mean age of $73.1 \pm 12.5$ years) with CDB and hospitalized between January 2004 and May 2019 were analyzed. The subjects were divided into two groups: the elderly (274 individuals aged $\geq 75$ years; mean age, $82.1 \pm 5.3$ years) and non-elderly (245 individuals aged <75 years; mean age, $63.0 \pm 10.3$ years) groups. Primary outcomes were early and late rebleeding rates, and secondary outcomes were the risk factors for late rebleeding in elderly individuals. Rebleeding occurring within 30 days of hospitalization was defined as early rebleeding, whereas rebleeding occurring after 31 days was defined as late rebleeding.

Results: The early rebleeding rates were $30.6 \%$ and $33.1 \%(p=0.557)$ in the elderly and non-elderly groups, respectively. The late rebleeding rates were $42.3 \%$ and $30.6 \%(p=0.005)$ in the elderly and nonelderly groups, respectively. The 3-year recurrence-free survival was $63.6 \%$ in the elderly group and $75.6 \%$ in the non-elderly group (log-rank test: $p<0.001)$. Multivariate analysis revealed the use of non-steroidal anti-inflammatory drugs (NSAIDs) [odds ratio (OR), 3.55], chronic kidney disease (OR, 2.89), and presence of bilateral diverticula $(\mathrm{OR}, 1.83)$ as the independent risk factors for late rebleeding in elderly individuals.

Conclusions: Elderly individuals with CDB require careful follow-up even after discharge. Furthermore, it is important to consider discontinuing NSAIDs to prevent rebleeding.
\end{abstract}

\section{Keywords}

colonic diverticular bleeding, elderly patients, rebleeding, non-steroidal anti-inflammatory drug, bilateral diverticula

J Anus Rectum Colon 2021; 5(2): 148-157

\section{Introduction}

Recently, the aging society resulting from the declining birth rate and prolonged mean life span has become a problem worldwide[1]. Japan is one of the rapidly aging coun- tries in the world. The prevalence of diverticula increases with age, and the aging of society in Japan has increased the occurrence of colonic diverticular bleeding (CDB)[2,3]. $\mathrm{CDB}$ is the most frequent type of lower gastrointestinal bleeding (LGIB)[4], and its risk factors include the use of 
non-steroidal anti-inflammatory drugs (NSAIDs) and aspirin[5,6]. Further, patients with CDB have a high rebleeding rate after discharge, and the reported rebleeding rates after 1 year range from $3.8 \%$ to $42 \%$ [7-14]. Repeated hospitalization due to CDB impairs elderly individuals from doing the activities of daily living. To date, few studies have focused on the characteristics of CDB in the elderly individuals. The Japan Gastroenterological Association's guidelines for CDB and colonic diverticulitis do not mention the characteristics of CDB in elderly individuals[8]. Therefore, in the study, we examined the difference between elderly and non-elderly individuals with $\mathrm{CDB}$ and identified the clinical characteristics of CDB in individuals aged $\geq 75$ years.

\section{Methods}

\section{Study design}

This retrospective case-control study was conducted at a single tertiary center in Japan and in accordance with the Declaration of Helsinki. The local ethics committee of our hospital approved the study protocol. Informed consent was obtained in the form of opt-out on the website. All authors had access to the study data and approved the final draft of the manuscript.

\section{Patients and data collection}

The study sample included patients aged $\geq 18$ years who were diagnosed with CDB and required hospitalization between January 2004 and May 2019. Those who could be followed up for at least 6 months after discharge were recruited. Recruited patients in this study partly overlapped with those in a previous report[15]. Hospitalization was recommended for all patients who presented to the hospital with LGIB and absence of abdominal pain and in whom the source of bleeding was unclear on abdominal computed tomography (CT) and anoscopy examination, regardless of the presence or absence of shock. The CDB diagnostic criteria were as follows: (i) definitive CDB (an active bleeding, nonbleeding visible vessel, and adherent clot observed from a specific diverticulum by colonoscopy)[16] and (ii) presumptive $\mathrm{CDB}$ (the source of bleeding could not be identified by colonoscopy and no other lesion could be observed that could cause bloody stools). Patients who required hospitalization were classified into two groups according to age: the elderly group that comprised patients aged $\geq 75$ years and the non-elderly group that comprised those aged $<75$ years. In each group, we examined patient data including sex, average age, performance status, comorbidities, the presence or absence of shock on or after admission, hemoglobin $(\mathrm{Hb})$ level on admission, blood transfusion dose during hospitalization, length of hospitalization, mortality, the presence or absence of bilateral diverticula, and oral agents taken includ- ing antithrombotic agents and NSAIDs. Furthermore, we examined the timing of colonoscopy, rate of identification of the bleeding source, bleeding site, type of stigmata of recent hemorrhage (SRH), hemostasis method, success rate of endoscopic treatment, and rebleeding rate. Patient data were retrospectively collected using the endoscopy database NEXUS $^{\circledR}$ (FUJIFILM Holdings Co., Tokyo, Japan) and the patients' electronic medical records. Shock was defined as a shock index of $>1$ due to bleeding. Shock index is defined as the ratio of heart rate to systolic blood pressure[17]. Chronic kidney disease (CKD) was considered to be present in patients undergoing hemodialysis or peritoneal dialysis or in those with an estimated glomerular filtration rate of $<60$ $\mathrm{mL} / \mathrm{min}$. "Bilateral diverticula" was defined as the confirmation of diverticula in both the right and left colons using CT on admission. Mortality was defined as death within 30 days of hospitalization.

\section{Colonoscopy}

All patients underwent colonoscopy after admission. Before colonoscopy, an intestinal lavage solution containing 2 $\mathrm{L}$ of polyethylene-glycol (PEG) was administered. If there was no history of renal failure or allergy to the contrast medium, all patients underwent contrast-enhanced CT at hospital arrival. When there was extravasation on contrastenhanced CT or when the vital signs were unstable, colonoscopy was performed without PEG at the discretion of the attending physician. PCF-Q260AZI or PCF-290AZI (Olympus Co., LTD, Tokyo, Japan) was used for colonoscopy. When SRH were identified, endoscopic hemostasis was performed using a hemoclip[18-20] or endoscopic band ligation (EBL)[7,21]. The clipping method used was the direct method, in which the blood vessels within diverticula were directly clipped[19,20]. The indirect method was used only for patients in whom the direct method was difficult to perform. The HX-610-135S or HX-610-135 device (Olympus Co., Ltd., Tokyo, Japan) was used as the hemoclip. The EBL method was introduced in 2015 as a method for endoscopic hemostasis; however, since its introduction, there was one case of delayed perforation following EBL[22]. Therefore, EBL was subsequently discontinued and clipping method was mainly used. Interventional radiology (IVR) or surgery was required when endoscopic hemostasis was difficult.

\section{Outcomes}

The primary outcomes were early and late rebleeding rates, and the secondary outcomes were the risk factors of late rebleeding in all patients and elderly patients. Early rebleeding was defined as bloody stools occurring within 30 days after admission or a reduction in $\mathrm{Hb}$ to $\geq 2 \mathrm{~g} / \mathrm{dL}$ on blood tests. Late rebleeding was defined as new bloody stools due to CDB occurring 31 days or later after admis- 


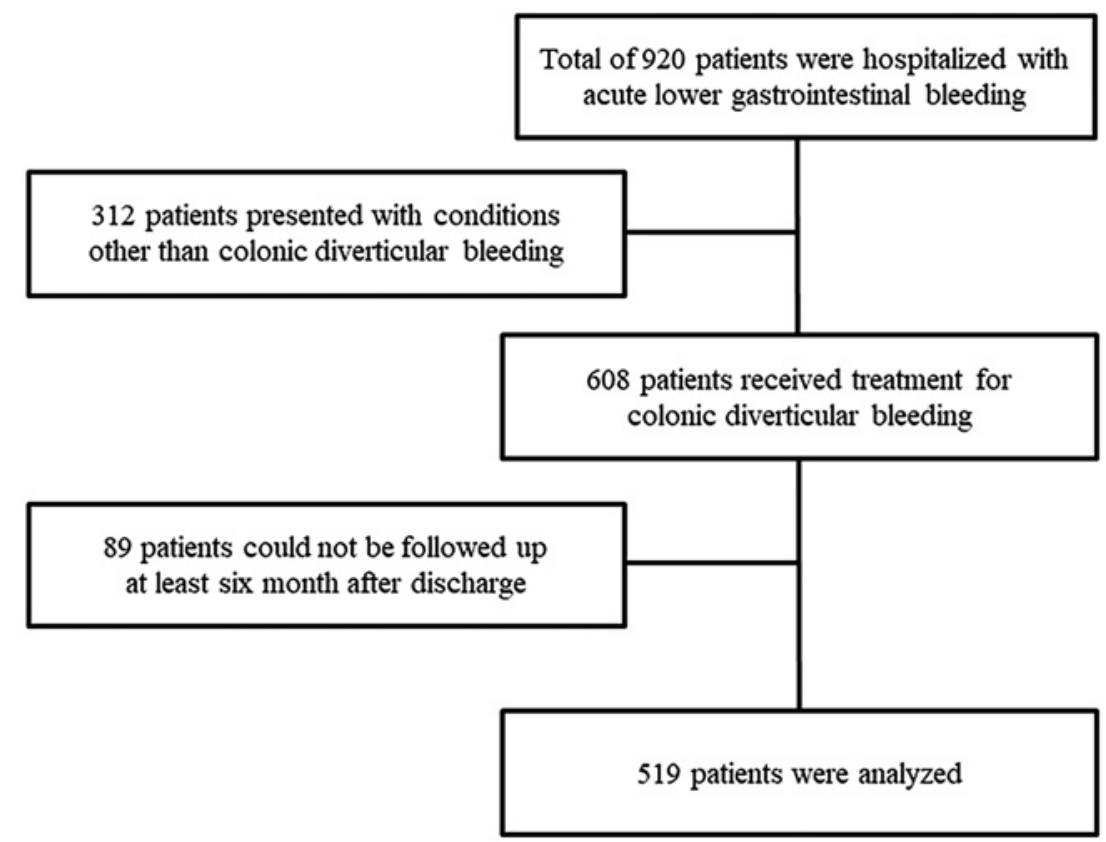

Figure 1. Flowchart of patient enrollment.

sion.

\section{Statistical analysis}

Results are presented as median and average for continuous variables. $\chi^{2}$-test and Fisher's exact test were used to compare categorical data, and Student's $t$-test and MannWhitney $U$-test were used to compare continuous data. Logistic regression analysis was performed to calculate the odds ratios (OR) of the risk factors for late rebleeding in all patients and in elderly patients with CDB. Furthermore, multivariate analysis was performed for risk factors that demonstrated statistical significance on univariate analysis. Comparison of the recurrence-free survival period was performed by log-rank test using Kaplan-Meier method. $P$ values of $<0.05$ were used to indicate statistical significance. Statistical analyses were performed using Statistical Package for the Social Sciences (version 22.0; IBM Corp., Armonk, NY, USA).

\section{Results}

\section{Patient characteristics}

Figure 1 shows patient enrollment. During the study period, 608 patients received treatment for CDB. Among them, 519 patients (356 men and 163 women; mean age, $73.1 \pm$ 12.5 years) who could be followed up for at least 6 months after discharge were recruited. The clinical characteristics of the patients are summarized in Table 1 . The elderly group comprised 274 patients, whereas the non-elderly group comprised 245 patients with mean ages of $82.1 \pm 5.3$ and $63.0 \pm$
10.3 years, respectively. The non-elderly group had a significantly higher proportion of patients with performance status scores of 0 and 1 than the elderly group. The elderly group had significantly more patients with underlying comorbidities such as hypertension, CKD, cardiovascular disease, respiratory disease, and malignant disease than the non-elderly group. Furthermore, the elderly group had significantly more patients taking antithrombotic agents, particularly aspirin ( $p$ $<0.001)$. Moreover, the percentage of patients taking NSAIDs was $20.8 \%$ and $8.9 \%$ in the elderly and non-elderly group, respectively, indicating a significant difference between the groups $(p<0.001)$. Note that the elderly group had significantly more patients with bilateral diverticula than the non-elderly group $(p<0.001)$. Moreover, no significant difference in the proportion of patients with a shock index of $>1$ was observed between the groups; however, the $\mathrm{Hb}$ level on admission was significantly lower in the elderly group than in the non-elderly group $(10.84 \pm 1.88$ vs. 11.90 $\pm 2.41 \mathrm{~g} / \mathrm{dL} ; p<0.001)$. The mean volume of blood transfusion was significantly higher in the elderly group than in the non-elderly group $(1.70 \pm 3.69$ vs. $1.01 \pm 2.29$ pacs; $p=$ $0.003)$. In this study, all subjects underwent colonoscopy after hospitalization. The time from admission to colonoscopy was $17.3 \pm 21.3 \mathrm{~h}$ in the elderly group and $15.8 \pm 17.8 \mathrm{~h}$ in the non-elderly group, with no significant difference between the groups $(p=0.465)$. The PEG administration rate before colonoscopy in both groups exceeded $80 \%$, with no significant difference observed $(p=0.717)$. The bleeding source was identified in $45.6 \%$ of the participants in the elderly group, which was not significantly different from $40.4 \%$ in the non-elderly group $(p=0.231)$. The mean length of 
Table 1. Clinical Characteristics of Patients.

\begin{tabular}{|c|c|c|c|c|}
\hline \multicolumn{2}{|c|}{ Characteristics } & \multirow{2}{*}{$\begin{array}{l}\text { Elderly group } \\
\qquad(\mathrm{N}=274) \\
174(63.5 \%)\end{array}$} & \multirow{2}{*}{$\begin{array}{c}\text { Non-elderly group } \\
(\mathrm{N}=245)\end{array}$} & \multirow{2}{*}{$\begin{array}{r}p \text { value } \\
0.010\end{array}$} \\
\hline Sex & Male & & & \\
\hline & Female & $100(36.5 \%)$ & $63(25.7 \%)$ & \\
\hline Age & Average \pm SD & $82.1 \pm 5.3$ & $63.0 \pm 10.3$ & $<0.001$ \\
\hline \multirow[t]{4}{*}{ Performance status } & 0 & $249(90.8 \%)$ & $239(97.6 \%)$ & 0.001 \\
\hline & 1 & $12(4.3 \%)$ & $2(0.8 \%)$ & 0.012 \\
\hline & 2 & $10(3.6 \%)$ & $3(1.2 \%)$ & 0.077 \\
\hline & 3 & $4(1.3 \%)$ & $1(0.4 \%)$ & 0.489 \\
\hline \multirow[t]{8}{*}{ Comorbidities } & Hypertension & $215(78.4 \%)$ & $128(52.3 \%)$ & $<0.001$ \\
\hline & Diabetes mellitus & $45(16.4 \%)$ & $47(19.1 \%)$ & 0.411 \\
\hline & Chronic kidney disease & $129(47.0 \%)$ & $73(29.7 \%)$ & $<0.001$ \\
\hline & Cardiovascular disease & $79(28.8 \%)$ & $23(9.4 \%)$ & $<0.001$ \\
\hline & Cerebrovascular disease & $42(15.3 \%)$ & $35(14.2 \%)$ & 0.738 \\
\hline & Respiratory disease & $21(7.7 \%)$ & $3(1.2 \%)$ & $<0.001$ \\
\hline & Liver cirrhosis & $2(0.7 \%)$ & $4(1.6 \%)$ & 0.336 \\
\hline & Malignant disease & $31(11.3 \%)$ & $10(4.0 \%)$ & 0.002 \\
\hline \multirow[t]{7}{*}{ Medication } & Antithrombotic agents & $142(51.8 \%)$ & $76(31.0 \%)$ & $<0.001$ \\
\hline & Aspirin & $95(34.7 \%)$ & $52(21.2 \%)$ & $<0.001$ \\
\hline & Thienopyridine & $24(8.8 \%)$ & $18(7.3 \%)$ & 0.556 \\
\hline & Warfarin & $30(10.9 \%)$ & $18(7.3 \%)$ & 0.157 \\
\hline & DOACs & $16(5.8 \%)$ & $10(4.1 \%)$ & 0.359 \\
\hline & DAPT & $18(6.6 \%)$ & $14(5.7 \%)$ & 0.686 \\
\hline & NSAIDs & $57(20.8 \%)$ & $22(8.9 \%)$ & $<0.001$ \\
\hline Diverticula & Bilateral & $144(52.5 \%)$ & $22(8.9 \%)$ & $<0.001$ \\
\hline Shock & Shock index $>1$ & $38(13.8 \%)$ & $33(13.4 \%)$ & 0.894 \\
\hline $\mathrm{Hb}$ on admission & $\mathrm{g} / \mathrm{dL}$ (average $\pm \mathrm{SD}$ ) & $10.84 \pm 1.88$ & $11.90 \pm 2.41$ & $<0.001$ \\
\hline Blood transfusion & Pacs (average $\pm \mathrm{SD}$ ) & $1.70 \pm 3.69$ & $1.01 \pm 2.29$ & 0.003 \\
\hline Time to colonoscopy & Average $\pm \mathrm{SD}$ (hour) & $17.3 \pm 21.3$ & $15.8 \pm 17.8$ & 0.465 \\
\hline PEG administration & & $226(82.4 \%)$ & $205(83.7 \%)$ & 0.717 \\
\hline Bleeding source & Identification rate & $125(45.6 \%)$ & $99(40.4 \%)$ & 0.231 \\
\hline Length of hospital stay & Days (average \pm SD) & $11.8 \pm 10.1$ & $10.2 \pm 5.7$ & 0.028 \\
\hline Mortality & & $4(1.4 \%)$ & $1(0.4 \%)$ & 0.220 \\
\hline
\end{tabular}

$\mathrm{Hb}$, hemoglobin; PEG, polyethylene glycol; DOACs, direct oral anticoagulants; DAPT, dual anti-platelet therapy; NSAIDs, non-steroidal anti-inflammatory drugs

hospitalization was significantly longer in the elderly group than in the non-elderly group $(11.8 \pm 10.1$ vs. $10.2 \pm 5.7$ days; $p=0.028)$. Moreover, no significant difference in the mortality rate was observed between the elderly and nonelderly groups $(1.4 \%$ vs. $0.4 \% ; p=0.220)$, and not a single case of death directly caused by bleeding was noted in either group.

Table 2 shows the results of endoscopic treatment. In $44.0 \%$ of participants in the elderly group, the bleeding site was identified in the left colon. This proportion was significantly higher than that $(20.2 \%)$ of the non-elderly group ( $p$ $<0.001$ ). Endoscopic hemostasis was performed on all patients in whom SRH was identified. In terms of the endoscopic hemostasis method used, hemostasis using a hemoclip was frequently performed in both groups with no significant difference observed between the two groups ( $p=$ 0.215). Furthermore, regarding the clip method, the direct method was performed in 106 patients $(94.6 \%)$ in the elderly group and in 88 patients $(93.6 \%)$ in the non-elderly group $(p=0.773)$. In the elderly group, there were significantly more cases of active bleeding; however, endoscopic treatment was unsuccessful in 15 patients $(12 \%)$ in the elderly group and in 8 patients $(8.1 \%)$ in the non-elderly group, with no statistically significant difference $(p=0.382)$. EBL treatment was unsuccessful only in one patient in the elderly group. In case that endoscopic treatment was unsuccessful, IVR and surgery were selected as additional treatment in both groups.

\section{Outcome}

The primary and secondary outcomes are presented in Table 3. No statistically significant difference in the early rebleeding rate was observed between the elderly and nonelderly groups (30.6\% vs. $33.1 \% ; p=0.557)$. In addition, 
Table 2. Results of Endoscopic Treatment for Patients with SRH.

\begin{tabular}{llccc}
\hline \multicolumn{1}{c}{ Characteristics } & $\begin{array}{c}\text { Elderly group } \\
(\mathrm{N}=125)\end{array}$ & $\begin{array}{c}\text { Non-elderly group } \\
(\mathrm{N}=99)\end{array}$ & $p$ value \\
\hline Bleeding site & Right colon & $70(56.0 \%)$ & $79(79.8 \%)$ & $<0.001$ \\
& Left colon & $55(44.0 \%)$ & $20(20.2 \%)$ & \\
Type of SRH & Active bleeding & $83(66.4 \%)$ & $49(50.0 \%)$ & 0.010 \\
& Visible vessel & $15(12.0 \%)$ & $14(14.4 \%)$ & 0.635 \\
& Adherent clot & $27(21.6 \%)$ & $36(35.6 \%)$ & 0.014 \\
Endoscopic hemostasis method & Hemoclip & $112(89.6 \%)$ & $94(95.0 \%)$ & 0.215 \\
& Band ligation & $13(10.4 \%)$ & $5(5.1 \%)$ & 0.215 \\
Endoscopic treatment & Success & $110(88.0 \%)$ & $91(91.9 \%)$ & 0.382 \\
& Fail & $15(12.0 \%)$ & $8(8.1 \%)$ & \\
Additional treatment & IVR & $13(10.4 \%)$ & $6(6.0 \%)$ & 0.335 \\
& Surgery & $2(1.6 \%)$ & $2(2.0 \%)$ & 1.000 \\
\hline
\end{tabular}

SRH, stigmata of recent hemorrhage; IVR, interventional radiology

Table 3. Early and Late Rebleeding Rate.

\begin{tabular}{llccc}
\hline & & $\begin{array}{c}\text { Elderly group } \\
(\mathrm{N}=274)\end{array}$ & $\begin{array}{c}\text { Non-elderly group } \\
(\mathrm{N}=245)\end{array}$ & $p$ value \\
\hline Early rebleeding & & $84(30.6 \%)$ & $81(33.1 \%)$ & 0.557 \\
$\quad$ Period until rebleeding & Median (range: days) & $2(1-14)$ & $1(0-23)$ & 0.177 \\
Rebleeding times & Median (range) & $1(1-6)$ & $1(1-8)$ & 0.313 \\
Late rebleeding & & $116(42.3 \%)$ & $75(30.6 \%)$ & 0.005 \\
$\quad$ Period until rebleeding & Median (range: months) & $12(1-146)$ & $15(1-132)$ & 0.850 \\
Rebleeding times & Median (range) & $1(1-10)$ & $1(1-9)$ & 0.301 \\
Follow-up period & Median (range: months) & $34(6-207)$ & $42.5(6-185)$ & 0.134 \\
\hline
\end{tabular}

both groups had a median number of rebleeding episode of one $(p=0.313)$. The late rebleeding rate was $42.3 \%$ in the elderly group and $30.6 \%$ in the non-elderly group, indicating a statistically significant difference $(p=0.005)$. No statistically significant difference in the time to rebleeding was observed between the elderly and non-elderly groups (12 months vs. 15 months; $p=0.850$ ). No statistically significant difference in the follow-up period was observed between the elderly and non-elderly groups (34 months vs. 42.5 months; $p=0.134$ ).

The results of univariate analysis for the risk factors of late rebleeding in all patients, as secondary outcomes, are presented in Table 4. A total of 191 patients experienced late rebleeding, whereas 328 did not. In univariate analysis, statistically significant differences were observed in terms of age $\geq 75$ years $(p=0.005)$, CKD $(p<0.001)$, cardiovascular disease $(p=0.030)$, use of NSAIDs $(p<0.001)$, and the presence of bilateral diverticula $(p<0.001)$. The results of multivariate analysis are presented in Table 5. Multivariate analysis revealed that the risk factors for late rebleeding in all patients were CKD (OR, 2.221; 95\% CI, 1.493-3.270; $p$ $<0.001$ ), use of NSAIDs (OR, 2.273; 95\% CI, 1.365-3.783; $p<0.002$ ), and bilateral diverticula (OR, 1.985; 95\% CI, $1.361-2.895 ; p<0.001)$. A statistically significant difference was not observed in elderly aged $\geq 75$ years (OR, 1.225; $95 \%$ CI, 0.845-1.862; $p=0.260$ ). The results of univariate analysis for the risk factors of late rebleeding in elderly individuals are presented in Table 6. In the elderly group, 116 patients experienced late rebleeding, whereas 158 did not. Univariate analysis revealed statistically significant differences in CKD $(p<0.001)$, cardiovascular disease $(p=$ $0.041)$, use of NSAIDs $(p<0.001)$, and the presence of bilateral diverticula $(p=0.049)$. The results of the multivariate analysis are presented in Table 7. Multivariate analysis showed that the risk factors for late rebleeding in the elderly group were CKD (OR, 2.889; 95\% CI, 1.687-4.949; $p<$ 0.001 ), use of NSAIDs (OR, 3.550; 95\% CI, 1.865-6.757; $p$ $<0.001)$, and bilateral diverticula (OR, 1.836; 95\% CI, $1.081-3.120 ; p=0.025)$. In the follow-up examinations over the course of 3 years, the recurrence-free survival rates at the 1 st, 2 nd, and 3 rd years were $77.1 \%, 67.2 \%$, and $63.6 \%$, respectively, in the elderly group, and $85.8 \%, 78.4 \%$, and $75.6 \%$, respectively, in the non-elderly group (Figure 2). The elderly group showed higher frequencies of late rebleeding than the non-elderly group (log-rank test: $p<0.001)$. 
Table 4. Risk Factors for Late Rebleeding in All Patients Using Univariate Analysis.

\begin{tabular}{|c|c|c|c|}
\hline Variables & $\begin{array}{l}\text { With recurrent bleeding } \\
\qquad(\mathrm{N}=191)\end{array}$ & $\begin{array}{l}\text { Without recurrent bleeding } \\
\qquad(\mathrm{N}=328)\end{array}$ & $p$ value \\
\hline Sex Male & $134(70.1 \%)$ & $222(67.7 \%)$ & 0.558 \\
\hline Female & $57(29.9 \%)$ & $106(32.3 \%)$ & \\
\hline Age $\geq 75$ & $116(60.7 \%)$ & $158(48.1 \%)$ & 0.005 \\
\hline$<75$ & $75(39.3 \%)$ & $170(51.9 \%)$ & \\
\hline \multicolumn{4}{|l|}{ Comorbidities } \\
\hline Hypertension & $128(67.0 \%)$ & $215(65.5 \%)$ & 0.733 \\
\hline Diabetes mellitus & $28(14.7 \%)$ & $64(19.5 \%)$ & 0.162 \\
\hline Chronic kidney disease & $99(51.8 \%)$ & $103(31.4 \%)$ & $<0.001$ \\
\hline Cardiovascular disease & $47(24.6 \%)$ & $55(16.7 \%)$ & 0.030 \\
\hline Cerebrovascular disease & $27(14.1 \%)$ & $45(13.7 \%)$ & 0.894 \\
\hline Respiratory disease & $12(6.3 \%)$ & $12(3.6 \%)$ & 0.169 \\
\hline \multicolumn{4}{|l|}{ Medication } \\
\hline Antithrombotic agents & $79(41.3 \%)$ & $139(42.3 \%)$ & 0.820 \\
\hline Aspirin & $57(29.8 \%)$ & $90(27.4 \%)$ & 0.582 \\
\hline Thienopyridine & $17(8.9 \%)$ & $25(7.6 \%)$ & 0.606 \\
\hline Warfarin & $15(7.8 \%)$ & $33(10.0 \%)$ & 0.402 \\
\hline DOACs & $11(5.8 \%)$ & $15(4.5 \%)$ & 0.550 \\
\hline DAPT & $13(6.8 \%)$ & $19(5.8 \%)$ & 0.643 \\
\hline NSAIDs & $44(23.0 \%)$ & $35(10.6 \%)$ & $<0.001$ \\
\hline \multicolumn{4}{|l|}{ Bilateral diverticula } \\
\hline Present & $112(58.6 \%)$ & $139(42.3 \%)$ & $<0.001$ \\
\hline Absent & $79(41.4 \%)$ & $189(57.7 \%)$ & \\
\hline \multicolumn{4}{|l|}{ Bleeding source } \\
\hline Identified & $84(44.0 \%)$ & $140(42.6 \%)$ & 0.089 \\
\hline Not identified & $107(56.0 \%)$ & $188(57.4 \%)$ & \\
\hline \multicolumn{4}{|l|}{ Type of SRH } \\
\hline Active bleeding & $55(28.8 \%)$ & $77(23.5 \%)$ & 0.179 \\
\hline Visible vessel & $8(4.2 \%)$ & $21(6.4 \%)$ & 0.327 \\
\hline Adherent clot & $21(10.1 \%)$ & $42(12.8 \%)$ & 0.542 \\
\hline \multicolumn{4}{|l|}{ CT extravasation } \\
\hline Present & $55(28.8 \%)$ & $73(22.2 \%)$ & 0.095 \\
\hline Absent & $136(71.2 \%)$ & $255(78.8 \%)$ & \\
\hline \multicolumn{4}{|c|}{ Endoscopic hemostasis method } \\
\hline Hemoclip & $76(40.0 \%)$ & $130(40.0 \%)$ & 0.971 \\
\hline Band ligation & $8(4.1 \%)$ & $10(3.0 \%)$ & 0.422 \\
\hline \multicolumn{4}{|l|}{ Endoscopic hemostasis } \\
\hline Success & $78(40.8 \%)$ & $123(37.5 \%)$ & 0.451 \\
\hline Fail & $9(4.7 \%)$ & $14(4.2 \%)$ & 0.667 \\
\hline \multicolumn{4}{|l|}{ Shock index $>1$} \\
\hline Present & $21(11.0 \%)$ & $50(15.2 \%)$ & 0.174 \\
\hline Absent & $170(89.0 \%)$ & $278(84.8 \%)$ & \\
\hline Blood transfusion $>2$ pacs & $58(30.3 \%)$ & $79(24.1 \%)$ & 0.117 \\
\hline
\end{tabular}

DOACs, direct oral anticoagulants; DAPT, dual anti-platelet therapy; NSAIDs, non-steroidal anti-inflammatory drugs; SRH, stigmata of recent hemorrhage

\section{Discussion}

In Japan, the number of CDB cases has been increasing due to aging of the population[2,3,8]. However, the characteristics of CDB in elderly individuals have not been completely elucidated. First, in this study, compared with the non-elderly group, there were significantly more patients with poor performance status, patients using antithrombotic agents or NSAIDs, and prevalence of an underlying condition in the elderly group. Furthermore, compared with the non-elderly group, there was significantly more bleeding from the left colon, active bleeding, and the mean blood transfusion amount after hospitalization in the elderly group. While there were various differences in patients' back- 
Table 5. Independent Risk Factors for Late Rebleeding in All Patients Using Multivariate Analysis.

\begin{tabular}{lccr}
\hline \multicolumn{1}{c}{ Variables } & Odds ratio & $\begin{array}{c}95 \% \text { confidence } \\
\text { interval }\end{array}$ & $p$ value \\
\hline Age $\geq 75$ & 1.225 & $0.845-1.862$ & 0.260 \\
Cardiovascular disease & 1.204 & $0.741-1.958$ & 0.453 \\
Chronic kidney disease & 2.221 & $1.493-3.270$ & $<0.001$ \\
NSAIDs & 2.273 & $1.365-3.783$ & 0.002 \\
Bilateral diverticula & 1.985 & $1.361-2.895$ & $<0.001$ \\
\hline
\end{tabular}

NSAIDs, non-steroidal anti-inflammatory drugs

grounds, no statistically significant difference was observed in the endoscopic hemostasis method, endoscopic treatment failure rate, early rebleeding rate, and mortality rate within 30 days of hospitalization in both groups. Kaise et al. reported that performing early endoscopic intervention and multimodal treatment, even in elderly individuals, can lower the risk of mortality[3]. In this study, in the elderly group, similar to the non-elderly group, we performed early colonoscopy and obtained comparable hemostasis results, which could have attributed to the absence of a difference in mortality.

Second, in this study, the late rebleeding rate was significantly higher in the elderly group $(42.3 \%)$ than in the nonelderly group $(30.6 \%)$ in univariate analysis. However, there was no statistically significant difference on multivariate analysis for age $\geq 75$ years. In both the elderly group and all patients, the independent risk factors for late rebleeding were bilateral diverticula, use of NSAIDs, and CKD. There were significantly more patients with these independent risk factors for late rebleeding in the elderly group than in the non-elderly group. This result may be attributed to the fact that the late rebleeding rate was significantly more common in the elderly group than in the non-elderly group on univariate analysis. With regard to age, reports have indicated that age is a risk factor for rebleeding. In a retrospective cohort study involving 14,925 individuals in the USA, the late rebleeding rate in individuals with $\mathrm{CDB}$ gradually increased with age[9]. Furthermore, it has been reported that LGIB increases the risk of death in elderly patients[23-26]; therefore, it is important to reduce the risk of rebleeding particularly in elderly patients. Regarding other risks of CBD, bilateral diverticula has been reported to be a risk factor for the onset of $\mathrm{CDB}[27,28]$. A cohort study of 1,514 patients by Niikura et al. reported that during the follow-up period of 46 months, 35 patients developed CDB and that the elderly aged $\geq 70$ years [hazard ratio (HR) 3.7] and bilateral diverticula (HR 2.4) were significant risks for the onset of CBD[27]. Furthermore, a retrospective age- and sexmatched, case-control study by Taki et al. reported that bilateral diverticulosis was a significant risk factor for the onset of CDB (OR, 3.0)[28]. In Asia, although right-side diver- ticula are common, with age, diverticula increase in number and extend to both sides[3]. How many diverticula could increase the risk of late rebleeding is unknown. However, bilateral diverticula suggested that it is a risk factor both of onset and late rebleeding of CBD. The use of NSAIDs is also a risk factor for rebleeding in patients with CDB[10-13]. In a study by Nagata et al., the rebleeding rate 1 year after discharge was $9.4 \%$ in the group with the discontinuation of NSAIDs and $77 \%$ in the group that continued the use of NSAIDs, and rebleeding was inhibited by the discontinuation of NSAIDs[10]. Tsuruoka et al. reported that the use of NSAIDs is a risk factor for rebleeding in individuals with $\mathrm{CDB}(\mathrm{OR}, 5.4)[13]$. In the American guideline, it is recommended to discontinue drugs that increase the risk of CDB[29]. Thus, the discontinuation of NSAIDs should be considered to prevent rebleeding. However, it is possible that the discontinuation of NSAIDs could result in the inability to control pain, thus reducing patients' quality of life particularly in elderly patients. Therefore, we believe that the discontinuation of NSAIDs should be carefully considered along with their risks and benefits. Furthermore, in this study, CKD was shown to be a risk factor for late rebleeding. Wada et al. reported that CKD was a risk factor for rebleeding in CBD (OR 2.3)[30]. Studies have also reported that diverticulosis develops at a young age in some patients with renal failure[31,32]. In patients with renal failure, the presence of uremic platelet dysfunction is considered as a cause of gastrointestinal bleeding[33]. As there could be a risk of rebleeding with $\mathrm{CBD}$ in $\mathrm{CKD}$ patients, careful follow-up is needed. Another risk factor for late rebleeding is a history of $\mathrm{CBD}[30]$, and the use of aspirin and other antithrombotic agents has also been reported[26,27,34]. However, in this study, antithrombotic agents, including aspirin, did not increase the risk of rebleeding. This may be because antithrombotic agents were discontinued or changed after discharge to reduce the risks. However, as risk reduction was not examined in detail, the specific reason is not clear on the basis of the results of the present study.

This study has several limitations. First, this was a retrospective single-center study. Second, this study was conducted over a long period of 15 years and included many physicians within the study period. Therefore, decisions on the timing of colonoscopy, hemostasis methods, and inpatient management were at the discretion of the attending physician and differed depending on the period. Third, among the endoscopic hemostasis methods, the EBL method was performed in only 18 patients. The EBL method has been reported to reduce the late rebleeding rate more than the hemoclip method[7]. Therefore, the rebleeding rates might have been reduced if the EBL method had been selected as the main hemostasis method.

In conclusion, no significant differences in the results of endoscopic treatment and early rebleeding rates were ob- 
Table 6. Risk Factors for Late Rebleeding in the Elderly Group Using Univariate Analysis.

\begin{tabular}{|c|c|c|c|}
\hline Variables & $\begin{array}{l}\text { With recurrent bleeding } \\
\qquad(\mathrm{N}=116)\end{array}$ & $\begin{array}{l}\text { Without recurrent bleeding } \\
\qquad(\mathrm{N}=158)\end{array}$ & $p$ value \\
\hline Sex Male & $80(69.0 \%)$ & $94(59.4 \%)$ & 0.107 \\
\hline Female & $36(31.0 \%)$ & $65(40.6 \%)$ & \\
\hline \multicolumn{4}{|l|}{ Comorbidities } \\
\hline Hypertension & $92(79.3 \%)$ & $123(77.8 \%)$ & 0.771 \\
\hline Diabetes mellitus & $19(16.4 \%)$ & $26(16.4 \%)$ & 0.986 \\
\hline Chronic kidney disease & $72(62.0 \%)$ & $57(36.1 \%)$ & $<0.001$ \\
\hline Cardiovascular disease & $41(35.3 \%)$ & $38(24.1 \%)$ & 0.041 \\
\hline Cerebrovascular disease & $17(14.6 \%)$ & $25(15.7 \%)$ & 0.790 \\
\hline Respiratory disease & $12(10.3 \%)$ & $9(5.7 \%)$ & 0.152 \\
\hline \multicolumn{4}{|l|}{ Medication } \\
\hline Antithrombotic agents & $59(50.8 \%)$ & $83(52.5 \%)$ & 0.307 \\
\hline Aspirin & $44(37.9 \%)$ & $51(32.2 \%)$ & 0.331 \\
\hline Thienopyridine & $13(11.2 \%)$ & $11(7.0 \%)$ & 0.219 \\
\hline Warfarin & $9(7.8 \%)$ & $21(13.3 \%)$ & 0.147 \\
\hline DOACs & $5(4.3 \%)$ & $11(7.0 \%)$ & 0.355 \\
\hline DAPT & $9(7.8 \%)$ & $9(6.7 \%)$ & 0.495 \\
\hline NSAIDs & $38(32.8 \%)$ & $19(12.0 \%)$ & $<0.001$ \\
\hline \multicolumn{4}{|l|}{ Bilateral diverticula } \\
\hline Present & $69(59.4 \%)$ & $75(47.5 \%)$ & 0.049 \\
\hline Absent & $47(40.6 \%)$ & $83(52.5 \%)$ & \\
\hline \multicolumn{4}{|l|}{ Bleeding source } \\
\hline Identified & $49(42.2 \%)$ & $76(48.1 \%)$ & 0.335 \\
\hline Not identified & $67(57.8 \%)$ & $82(51.9 \%)$ & \\
\hline \multicolumn{4}{|l|}{ Type of SRH } \\
\hline Active bleeding & $32(27.6 \%)$ & $51(32.2 \%)$ & 0.403 \\
\hline Visible vessel & $5(4.3 \%)$ & $10(6.3 \%)$ & 0.594 \\
\hline Adherent clot & $12(10.3 \%)$ & $15(9.5 \%)$ & 0.839 \\
\hline \multicolumn{4}{|l|}{ CT extravasation } \\
\hline Present & $35(30.2 \%)$ & $45(28.4 \%)$ & 0.760 \\
\hline Absent & $81(69.8 \%)$ & $113(71.6 \%)$ & \\
\hline \multicolumn{4}{|c|}{ Endoscopic hemostasis method } \\
\hline Hemoclip & $45(38.8 \%)$ & $67(42.4 \%)$ & 0.548 \\
\hline Band ligation & $4(3.4 \%)$ & $9(5.6 \%)$ & 0.387 \\
\hline \multicolumn{4}{|l|}{ Endoscopic hemostasis } \\
\hline Success & $46(40.0 \%)$ & $64(40.5 \%)$ & 0.887 \\
\hline Fail & $4(3.4 \%)$ & $11(7.0 \%)$ & 0.206 \\
\hline \multicolumn{4}{|l|}{ Shock index $>1$} \\
\hline Present & $15(12.9 \%)$ & $23(14.6 \%)$ & 0.700 \\
\hline Absent & $101(87.1 \%)$ & $135(85.4 \%)$ & \\
\hline Blood transfusion $>2$ pacs & $37(31.9 \%)$ & $60(37.9 \%)$ & 0.298 \\
\hline
\end{tabular}

DOACs, direct oral anticoagulants; DAPT, dual anti-platelet therapy; NSAIDs, non-steroidal anti-inflammatory drugs; SRH, stigmata of recent hemorrhage

Table 7. Independent Risk Factors for Late Rebleeding in the Elderly Group Using Multivariate Analysis.

\begin{tabular}{lccr}
\hline \multicolumn{1}{c}{ Variables } & Odds ratio & $\begin{array}{c}95 \% \text { confidence } \\
\text { interval }\end{array}$ & $p$ value \\
\hline Cardiovascular disease & 1.480 & $0.827-2.647$ & 0.187 \\
Chronic kidney disease & 2.889 & $1.687-4.949$ & $<0.001$ \\
NSAIDs & 3.550 & $1.865-6.757$ & $<0.001$ \\
Bilateral diverticula & 1.836 & $1.081-3.120$ & 0.025 \\
\hline
\end{tabular}

NSAIDs, non-steroidal anti-inflammatory drugs served between the elderly and non-elderly groups. However, the elderly group had a significantly higher late rebleeding rate than the non-elderly group. The risk factors for late rebleeding in both all patients and elderly individuals include the presence of bilateral diverticula, use of NSAIDs, and history of CKD. Elderly patients with CBD with these risk factors require a particularly careful followup, even after discharge. In addition, it is important to discontinue drugs that increase the risk of $\mathrm{CDB}$ to prevent 


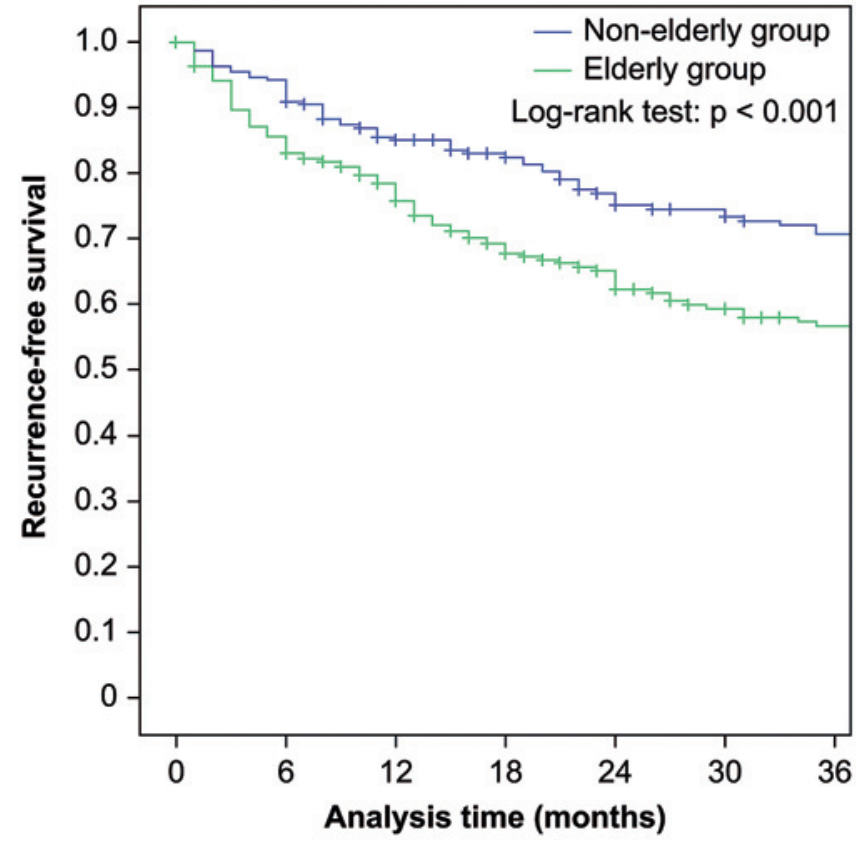

Figure 2. Recurrence-free survival rate between elderly and non-elderly patients.

rebleeding.

Acknowledgements

The authors thank Crimson Interactive Pvt. Ltd. (Ulatus) (www.ulatus.jp) for their assistance in manuscript translation and editing.

\section{Conflicts of Interest}

There are no conflicts of interest.

\section{Author Contributions}

The corresponding author had full access to all the data in the study and had final responsibility for the decision to submit for publication. All other authors have contributed to data collection and interpretation and critically reviewed the manuscript. All authors approved the final version of the manuscript and agree to be accountable for all aspects of the work in ensuring that questions related to the accuracy or integrity of any part of the work are appropriately investigated and resolved.

Approval by Institutional Review Board (IRB)

The local ethics committee of St. Marianna University School of Medicine approved the study protocol (approval number: 4775).

\section{Informed Consent}

Informed consent was obtained in the form of opt-out on the website.

\section{References}

1. Lutz W, Sanderson W, Scherbov S. The coming acceleration of global population ageing. Nature. 2008 Feb; 451(7179): 716-9.

2. Nagata N, Niikura R, Aoki T, et al. Increase in colonic diverticulosis and diverticular hemorrhage in an aging society: Lessons from a 9-year colonoscopic study of 28,192 patients in Japan. Int J Colorectal Dis. 2014 Mar; 29(3): 379-85.

3. Kaise M, Nagata N, Ishii N, et al. Epidemiology of colonic diverticula and recent advances in the management of colonic diverticular bleeding. Dig Endosc. 2020 Jan; 32(2): 240-50.

4. Longstreth GF. Epidemiology and outcome of patients hospitalized with acute lower gastrointestinal hemorrhage: a population-based study. Am J Gastroenterol. 1997 Mar; 92(3): 419-24.

5. Yuhara H, Corley DA, Nakahara F, et al. Aspirin and non-aspirin NSAIDs increase risk of colonic diverticular bleeding: a systematic review and meta-analysis. J Gastroenterol. 2014 Jun; 49(6): 992-1000.

6. Nagata N, Niikura R, Aoki T. Colonic diverticular hemorrhage associated with the use of nonsteroidal anti-inflammatory drugs, low-dose aspirin, antiplatelet drugs, and dual therapy. J Gastroenterol Hepatol. 2014 Oct; 29(10): 1786-93.

7. Nakano K, Ishii N, Ikeya $\mathrm{T}$, et al. Comparison of long-term outcomes between endoscopic band ligation and endoscopic clipping for colonic diverticular bleeding. Endosc Int Open. 2015 Oct; 3(5): E529-33.

8. Nagata N, Ishii N, Manabe N, et al. Guidelines for colonic diverticular bleeding and colonic diverticulitis: Japan Gastroenterological Association. Digestion. 2019 Jan; 99(1): 1-26.

9. Vajravelu RK, Mamtani R, Scott FI, et al. Incidence, risk factors, and clinical effects of recurrent diverticular hemorrhage: a large cohort study. Gastroenterology. 2018 Nov; 155(5): 1416-27.

10. Nagata N, Niikura R, Aoki T, et al. Impact of discontinuing nonsteroidal anti-inflammatory drugs on long-term recurrence in colonic diverticular bleeding. World J Gastroenterol. 2015 Jan; 21(4): 1292-8.

11. Niikura R, Nagata N, Yamada A, et al. Recurrence of colonic diverticular bleeding and associated risk factors. Colorectal Dis. 2012 Feb; 14(3): 302-5.

12. Okamoto $\mathrm{T}$, Watabe $\mathrm{H}$, Yamada $\mathrm{A}$, et al. The association between arteriosclerosis related diseases and diverticular bleeding. Int $\mathrm{J}$ Colorectal Dis. 2012 Sep; 27(9): 1161-6.

13. Tsuruoka N, Iwakiri R, Hara M, et al. NSAIDs are a significant risk factor for colonic diverticular hemorrhage in elder patients: evaluation by a case-control study. J Gastroenterol Hepatol. 2011 Jun; 26(6): 1047-52.

14. Poncet G, Heluwaert F, Voirin D, et al. Natural history of acute colonic diverticular bleeding: a prospective study in 133 consecutive patients. Aliment Pharmacol Ther. 2010 Aug; 32(3): 466-71.

15. Nakatsu S, Yasuda H, Maehata T, et al. Urgent computed tomography for determining the optimal timing of colonoscopy in patients with acute lower gastrointestinal bleeding. Intern Med. 2015 Jan; 54(6): 553-8.

16. Jensen DM, Ohning GV, Kovacs TO, et al. Natural history of definitive diverticular hemorrhage based on stigmata of recent hemorrhage and colonoscopic Doppler blood flow monitoring for risk stratification and definitive hemostasis. Gastrointest Endosc. 2016 Feb; 83(2): 416-23.

17. Allgower M, Burri C. ["Shock index"]. Dtsch Med Wochenschr. 1967 Oct; 92(43): 1947-50. German. 
18. Hokama A, Uehara T, Nakayoshi T, et al. Utility of endoscopic hemoclipping for colonic diverticular bleeding. Am J Gastroenterol. 1997 Mar; 92(3): 543-46.

19. Ishi N, Hirata N, Omata F, et al. Location in the ascending colon is a predictor of refractory colonic diverticular hemorrhage after endoscopic clipping. Gastrointestinal Endosc. 2012 Dec; 76(6): 1175-81.

20. Yen EF, Ladabaum U, Muthusamy VR, et al. Colonoscopic treatment of acute diverticular hemorrhage using endoclips. Dig Dis Sci. 2008 Sep; 53(9): 2480-5.

21. Setoyama T, Ishii N, Fujita Y. Enodoscopic band ligation (EBL) is superior to endoscopic clipping for the treatment of colonic diverticular hemorrhage. Surg Endosc. 2011 Nov; 25(11): 3574-8.

22. Sato Y, Yasuda H, Fukuoka A, et al. Delayed perforation after endoscopic band ligation for colonic diverticular hemorrhage. Clin J Gastroenterol. 2020 Feb; 13(1): 6-10.

23. Lenti MV, Pasina L, Cococcia S. Mortality rate and risk factors for gastrointestinal bleeding in elderly patients. Eur J Intern Med. 2019 Mar; 61: 54-61.

24. Niikura R, Yasunaga H, Yamaji Y, et al. Factors affecting in hospital mortality in patients with lower gastrointestinal tract bleeding: a retrospective study using a national database in Japan. J Gastroenterol. 2015 May; 50(5): 533-40.

25. Strate LL, Ayanian JZ, Koltler G, et al. Risk factors for mortality in lower intestinal bleeding. Clin Gastroenterol Hepatol. 2008 Sep; 6(9): 1004-10.

26. Aoki T, Nagata N, Niikura R, et al. Recurrence and mortality among patients hospitalized for acute lower gastrointestinal bleeding. Clin Gastroenterol Hepatol. 2015 Mar; 13(3): 488-94.e1.

27. Niikura R, Nagata N, Shimbo T, et al. Natural history of bleeding risk in colonic diverticulosis patients: a long-term colonoscopybased cohort study. Aliment Pharmacol Ther. 2015 May; 41(9): 888-94.

28. Taki M, Oshima T, Tozawa K, et al. Analysis of risk factors for colonic diverticular bleeding and recurrence. Medicine. 2017 Sep; 96(38): e8090.

29. Strate LL, Gralnek IM. ACG clinical guideline: management of patients with acute lower gastrointestinal bleeding. Am J Gastroenterol. 2016 Apr; 111(4): 459-74.

30. Wada M, Kato M, Hirai Y, et al. Initial management of colonic diverticular bleeding: observational study. Digestion. 2018 Jun; 98 (1): 41-7.

31. Abramson SJ, Berdon WE, Laffey K. Colonic diverticulitis in young patients with chronic renal failure and transplantation. Pediatr Radiol. 1991 Jul; 21(5): 353-4.

32. Saeed F, Agrawal N, Greenberg E, et al. Lower gastrointestinal bleeding in chronic hemodialysis patients. Int J Nephrol. 2011 Oct; 2011: 272535.

33. Luo JC, Leu HB, Hou MC, et al. Nonpeptic ulcer, nonvariceal gastrointestinal bleeding in hemodialysis patients. Am J Med. 2013 Mar; 126(3): e25-32.

34. Chan FK, Leung Ki EL, Wong GL, et al. Risks of bleeding recurrence and cardiovascular events with continued aspirin use after lower gastrointestinal hemorrhage. Gastroenterology. 2016 Aug; 151(2): 271-7.

Journal of the Anus, Rectum and Colon is an Open Access journal distributed under the Creative Commons Attribution-NonCommercial-NoDerivatives $4.0 \mathrm{In}$ ternational License. To view the details of this license, please visit (https://creativ ecommons.org/licenses/by-nc-nd/4.0/). 